\title{
Can FMA (Noise) 1989 Prevent Occupational Noise- Induced Hearing Loss? An Evaluation using Fault Tree Analysis
}

\author{
Ahmad MA ${ }^{a}$, Razali $A^{a}$ \\ ${ }^{a}$ Department of Otorhinolaryngology and Head \& Neck Surgery, Kulliyyah of Medicine, International Islamic \\ University Malaysia, 25200 Kuantan, Pahang, Malaysia.
}

\begin{abstract}
Introduction: Factory and Machinery Act (Noise Exposure) Regulation 1989 (FMA [Noise] 1989) has been implemented in Malaysia for nearly 30 years, but noise-induced hearing loss (NIHL) cases is still rising. Fault tree analysis is a top-down approach to analyzing incidences of 'failures', starting with establishing the single top event that will eventually cause NIHL, followed by identification of the contributing factors to the top event which are the immediate or basic events. Through its visual, structural and deductive approach; FTA is able to depict the temporal sequence of events and their interactions in a formal and logical hierarchy. Materials and Methods: Employees with permanent standard threshold shifts (PSTS) underwent further assessment confirming the presence of NIHL. A single common fault tree was constructed based on six cases of PSTS. The top event is the PSTS. Intermediate and basic events were identified and mapped with relevance to the provisions in the FMA (noise) 1989 indicating how failed control measures have resulted in the PSTS cases. Results: The constructed fault tree with its branches illustrated how breach or noncompliance of FMA (Noise) 1989 resulted in the eventual top event (NIHL). Conclusion: FTA provides a standardized perspective of errors within the system in preventing NIHL.
\end{abstract}

KEYWORDS: FTA, NIHL, FMA (Noise) 1989

\section{INTRODUCTION}

Historically, Fault Tree Analysis or FTA was developed by Bell Labs in $1962{ }^{1}$ to study failure modes in a launch control system of American intercontinental ballistic missile, the mainstay of the United States deterrent in the midst of the cold war. ${ }^{2}$ FTA is known for its unique "top-down" approach in analyzing failure modes. Construction of fault tree starts with establishing a single top event, which is system failure. It is followed by identification of the contributing factors; the immediate or basic events resulting in the top event. The immediate events are connected to the top event via logic gates, the "OR or AND gates". Once the first level of events directly contributing

Corresponding author:

Assoc. Prof. Dr. Ailin Razali

Dept. of Otorhinolaryngology and Head \& Neck Surgery, Kulliyyah of Medicine, International Islamic University Malaysia, 25200 Kuantan, Pahang, Malaysia.

Tel : 609 - 5704451

Email : ailin@iium.edu.my to the top event has been established, each event will be examined to decide whether it could be further broken down to more elementary events contributing to the intermediate event occurrence. The procedure of analyzing every intermediate event is continued until all branches have been terminated in independent primary events known as the basic events. $^{3}$

By assigning probability value to each of the event, FTA can be further used to provide quantitative analysis of the probability of occurrence of the top event. ${ }^{3}$ These values are normally obtained either from empirical data $^{4}$ or from a subject matter expert. ${ }^{5}$ By applying the probability value for each event, interventions can be targeted toward high probability events, with outcomes monitored by subsequent probability assessments.

Even though FTA is best known in the commercial nuclear power industry, ${ }^{5}$ its potential applicability in healthcare is immense. Rogith et $\mathrm{al}^{6}$ in their study on 10 published medical diagnostic errors have 
demonstrated that FTA; through its visual, structural and deductive approach, was able to depict the temporal sequence of events and their interactions in a formal logical hierarchy. They were also able to combine 10 different fault trees into a single fault tree showing how FTA can include common contributing factors and pathways across multiple cases of diagnostic error. The applicability of FTA in providing a standardized perspective of errors in preventing wrong-site surgery has also been discussed. ${ }^{7}$ They observed that any process with redundancy within a system is measured by the relative dominance of the "AND gates". The more "AND gates" in a system, the more errors or omissions that could theoretically be tolerated without the system failing. FTA was also used to determine preventability of pediatric readmission to the wards. ${ }^{8}$ In their study, the basic events are actually the root cause which can be used to decide whether readmissions are preventable. This will ultimately contribute to lowering per-capita cost of healthcare provision.

In this study, the authors would like to analyze 6 cases which resulted in permanent standard threshold shifts (PSTS) in a petrochemical plant in Malaysia which allegedly adopts stringent control measures against noise exposure. The control measures have been prescribed by the Factory and Noise (Noise Exposure) Regulation 1989 or FMA (Noise) 1989. ${ }^{9}$ PSTS is defined as permanent average shift of more than $10 \mathrm{~dB}$ at frequencies of 2000,3000 and $4000 \mathrm{~Hz}$ relative to the baseline audiogram in either ear. ${ }^{9}$ With elements of high noise exposure, sensorineural hearing loss, normal (Type A) tympanogram and no organic abnormality found by ENT Specialist, these cases fit in the diagnosis of NIHL. Even though there is no one specific diagnosis criterion of NIHL in Malaysia presently, the requirement to report cases of PSTS by FMA (Noise) $1989^{\circ}$ implies the importance of PSTS as an indicator of NIHL in a workplace. NIHL is irreversible and thus, early detection and intervention is critical for prevention. ${ }^{10}$ In this respect, PSTS provides the legal means for corrective measure to be taken. However, it is beyond the scope of this article to discuss on the various proposed criteria for NIHL, except that it is agreed that NIHL indicates high frequency loss. The authors are interested in demonstrating that FTA would be able to give a clear view on the propagation of what seems to be various unrelated events, but eventually would result in PSTS.

\section{MATERIALS AND METHODS}

Six employees with PSTS based on the screening PTA results were referred to the ENT Specialist and Audiologist. No other organic lesions were found by the ENT Specialist that could be responsible for the hearing loss. Diagnostic audiometry showed a sensorineural loss on the affected ears. Tympanometry test results were all normal (type "A"). Validation at site of noise exposure monitoring reports was also carried out. A single common Fault Tree was constructed based on the six cases of PSTS (Figure 1). The top event is the PSTS. The intermediate events were events which had directly contributed to the incident and these events were further broken down until the basic events were identified. Each event was then mapped with the relevant provision in the FMA (Noise) $1989^{\circ}$ to indicate how failed control measures have resulted in the said six cases of PSTS.

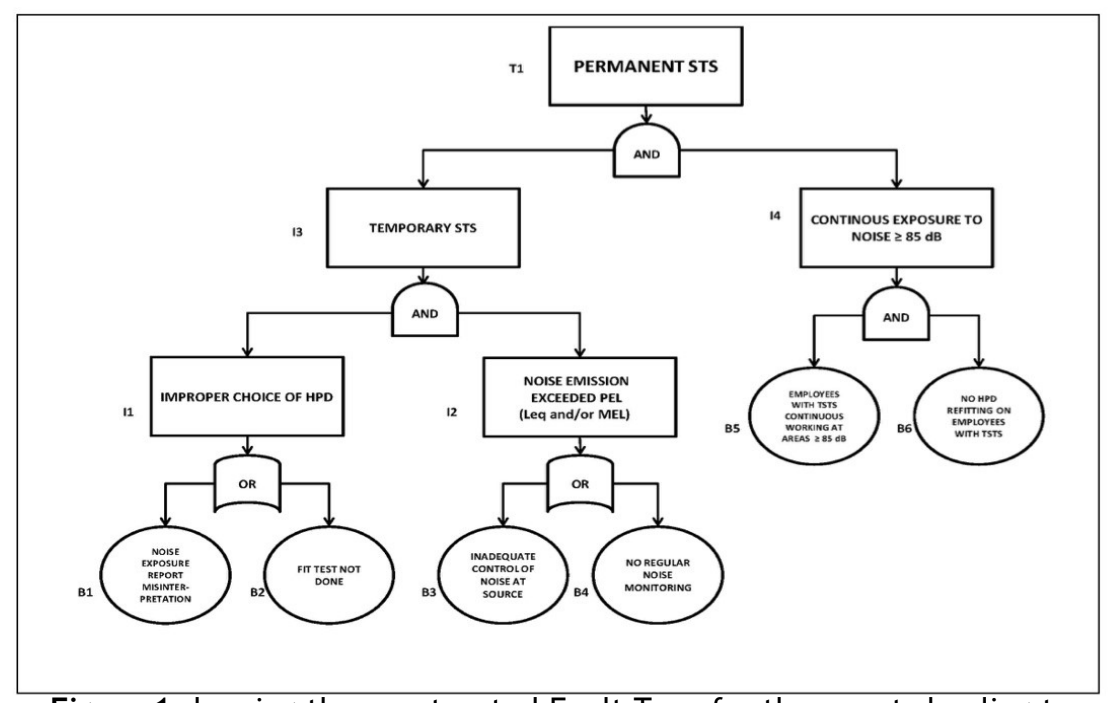

Figure 1 showing the constructed Fault Tree for the events leading to PSTS ( $B=$ Basic Event, I=Intermediate event, $T=$ Top Event 


\section{RESULTS}

Table I shows the investigation results of six PSTS cases. All cases showed a sensorineural loss with normal tympanogram. The control measure used was Hearing Protection Device (HPD). Calculation based on the Noise Reduction Ratio (NRR) provided by HPD (either ear muff or ear plug) showed that the protection against MEL of $115 \mathrm{~dB}$ was inadequate. ${ }^{11}$ It was not a practice for the employees to wear double protection during their working shift.

The fault tree was then constructed (Figure 1) with the identification of the top event - PSTS. It branched down to include various intermediate and basic events respectively. Since the objective of this article is to analyze the effectiveness of FMA (Noise) $1989^{\circ}$ in preventing $\mathrm{NIHL}$, the relevant Regulations in FMA (Noise) $1989^{\circ}$ will be assigned accordingly to each basic event to illustrate on how breach of or non-compliance with the provisions in FMA (Noise) 1989 Regulations $^{9}$ have resulted in the intermediate events, and eventually the top event. Attention must be given to these basic events which are the root causes of PSTS.

Preventing these root causes from materializing will mean that there will be no PSTS or even Temporary Threshold Shifts (TTS) cases on workplace. This is summarized in Table II.

Table I summarizes the findings on the six cases of permanent STS (PSTS)

\begin{tabular}{|c|c|c|c|c|c|c|c|c|}
\hline Employee & Work Unit & $\begin{array}{l}\text { *Area Noise } \\
\text { Level (dB) }\end{array}$ & $\begin{array}{c}* * \text { Leq8 hours } \\
(\mathrm{dB}) \text { at site }\end{array}$ & $\begin{array}{c}{ }^{* * *} M E L \\
\text { (dB) at } \\
\text { site }\end{array}$ & $\begin{array}{l}\text { NRR of HPD } \\
\text { used }\end{array}$ & ENT findings & $\begin{array}{c}\text { Audiologist find- } \\
\text { ings }\end{array}$ & Diagnosis \\
\hline $\bar{A}$ & $\begin{array}{c}\text { Export } \\
\text { Terminal }\end{array}$ & $78-80$ & 64.8 & 125 & $\begin{array}{l}\text { Ear plug }=25 \\
\text { Ear muff }=20\end{array}$ & Normal & \begin{tabular}{|l|} 
1. Sensorineural \\
hearing loss \\
2 . Absence of \\
second bend in \\
the right ear
\end{tabular} & $\begin{array}{c}\text { PSTS right } \\
\text { ear }\end{array}$ \\
\hline B & $\begin{array}{l}\text { Export } \\
\text { Terminal }\end{array}$ & $78-80$ & 64.8 & 125 & $\begin{array}{l}\text { Ear plug }=25 \\
\text { Ear muff }=20\end{array}$ & Normal & $\begin{array}{l}\text { Sensorineural } \\
\text { hearing loss }\end{array}$ & \begin{tabular}{|l|} 
Bilateral \\
PSTS
\end{tabular} \\
\hline $\mathrm{C}$ & Maintenance & $60-107$ & $35.9-90.5$ & $\begin{array}{l}89.2- \\
125.6\end{array}$ & $\begin{array}{l}\text { Ear plug }=25 \\
\text { Ear muff }=20\end{array}$ & Normal & $\begin{array}{l}\text { Sensorineural } \\
\text { hearing loss }\end{array}$ & $\begin{array}{c}\text { PSTS right } \\
\text { ear }\end{array}$ \\
\hline $\mathrm{D}$ & Maintenance & $60-107$ & $35.9-90.5$ & $\begin{array}{l}89.2- \\
125.6\end{array}$ & $\begin{array}{l}\text { Ear plug }=25 \\
\text { Ear muff }=20\end{array}$ & Normal & $\begin{array}{l}\text { Sensorineural } \\
\text { hearing loss }\end{array}$ & $\begin{array}{c}\text { PSTS right } \\
\text { ear }\end{array}$ \\
\hline $\mathrm{E}$ & Maintenance & $60-107$ & $35.9-90.5$ & $\begin{array}{l}89.2- \\
125.6\end{array}$ & $\begin{array}{l}\text { Ear plug }=25 \\
\text { Ear muff }=20\end{array}$ & Normal & $\begin{array}{l}\text { Sensorineural } \\
\text { hearing loss }\end{array}$ & \begin{tabular}{|l|} 
Bilateral \\
PSTS
\end{tabular} \\
\hline $\bar{F}$ & Maintenance & $60-107$ & $35.9-90.5$ & $\begin{array}{l}89.2- \\
125.6\end{array}$ & $\begin{array}{l}\text { Ear plug }=25 \\
\text { Ear muff }=20\end{array}$ & Normal & $\begin{array}{l}\text { Sensorineural } \\
\text { hearing loss }\end{array}$ & $\begin{array}{c}\text { PSTS right } \\
\text { ear }\end{array}$ \\
\hline
\end{tabular}

*Based on Area Noise Exposure Monitoring Report

** Based on Employee Noise Exposure Monitoring Report

*** All of the affected employees wear either ear muff or ear plug as the main control measure while working. Use of double protection was not practised.

\section{DISCUSSION}

The incident of TTS started with the basic events of $\mathrm{B} 1$ - B4, and then escalated to become PSTS through the events of B5 - B6. There were numerous regulations that have been breached, probably as a result of being overlooked or ignored. Interestingly, the three "AND gates", which should serve as strong deterrents (12) against PSTS were also violated. The seemingly unrelated six basic events actually acted in a parallel manner and escalated to become intermediate events.

There are some interesting facts that could be inferred from this fault tree. Performing and then combining both area and personal noise exposure monitoring results in a single report can lead to disastrous consequences. As a matter of fact, there is no mention for area noise monitoring in FMA (Noise) 1989. ${ }^{9}$ However, if performed, it can be used to estimate noise exposure when the noise levels are relatively constant and employees are not mobile, ${ }^{13}$ and both area and personal noise reports must be compiled in two separate reports. Area monitoring can also be used to delineate areas with high noise emission. But if employees move about in different areas, or the noise level tends to fluctuate over time, personal noise exposure is generally more accurate. On performing personal noise exposure, the monitoring must be based on all activities performed by the employees. ${ }^{9}$ 
Table II Describes the various basic events in the constructed Fault Tree and their relationship to the breach of provisions in FMA (Noise) 1989

\begin{tabular}{|c|c|c|}
\hline Basic Events & Description of Events & Breach of Provisions in FMA (Noise) 1989 \\
\hline B1 & $\begin{array}{l}\text { Noise exposure } \\
\text { misinterpretation }\end{array}$ & $\begin{array}{l}\text { Regulations } 8 \text { to } 14 \text { only require personal and not area noise } \\
\text { exposure monitoring to be conducted. By performing both area and } \\
\text { personal noise exposure monitoring, and documenting it in the one } \\
\text { same report resulted in confusion and finally misinterpretation of } \\
\text { the report's content }\end{array}$ \\
\hline B2 & Fit test not done & $\begin{array}{l}\text { Regulations } 17 \text { to } 19 \text { have spelt out the requirement, degree of } \\
\text { attenuation and HPD to correctly fit the employee. By not } \\
\text { performing the fit test, the adequacy of protection by the HPD } \\
\text { remained questionable. }\end{array}$ \\
\hline B3 & $\begin{array}{l}\text { Inadequate control of noise } \\
\text { at source }\end{array}$ & $\begin{array}{l}\text { Regulation } 16 \text { stated that engineering, followed by administrative or } \\
\text { both measures should be given priority in controlling noise exposure } \\
\text { at workplace. HPD which should be considered only if these } \\
\text { measures failed, was however given the priority in the hierarchy of } \\
\text { noise control }\end{array}$ \\
\hline B4 & No regular noise monitoring & $\begin{array}{l}\text { Regulation } 12 \text { requires that within } 6 \text { months of production, process, } \\
\text { equipment, control measures or personnel change in the factory, } \\
\text { additional monitoring must be conducted. Unfortunately, this was } \\
\text { not done }\end{array}$ \\
\hline B5 & $\begin{array}{l}\text { Employees with STS } \\
\text { continued working at areas } \\
\geq 85 \mathrm{~dB}\end{array}$ & $\begin{array}{l}\text { Regulation } 18(2) \text { prohibits employees from being exposed to noise } \\
\text { level at or above Action Level at any time once they have STS. } \\
\text { however, all the employees continued to work at their old workplace } \\
\text { as usual }\end{array}$ \\
\hline B6 & $\begin{array}{l}\text { No refitting of HPD on } \\
\text { employees with STS }\end{array}$ & $\begin{array}{l}\text { Regulation } 24 \text { (c) stated that employees with permanent STS must } \\
\text { be refitted and retrained in the use of a hearing protection device } \\
\text { once STS has been detected. In all the cases, this was not } \\
\text { performed. }\end{array}$ \\
\hline
\end{tabular}

The HPD fit test is relatively new and only commercially available around the year 2013.14 The importance of performing fit test has been demonstrated in events B6 and B2 in the constructed fault tree above (Figure 1). By conveniently assuming that all workers could be protected by the same HPD, the employer has ignored the fact of ear canal structure variations. ${ }^{15}$ It has been shown that the Employer A (Table I) has a distinct right ear canal shape which, if fit test was performed, would most likely require a customized HPD. This would have saved his ear from PSTS and NIHL. The other cases where PSTS seem to "favour" right rather than left ear was also investigated. In the absence of ear canal structure abnormality, the most likely explanation is the temporary removal of their right ear HPD when communicating using radio at areas with high noise. This could be addressed by advising the workers to minimize radio communication in noisy areas or by using a radio with headphone jack. The results of audiometric testing were depicted in the fault tree twice at 11 and T1. This shows that audiometric test results are not the basic events, but rather effects from the basic events. For that reason, all the six basic events must be carefully examined thoroughly to get to the root cause for each of the PSTS cases found.

\section{CONCLUSION}

FTA has been demonstrated to be a valuable tool in analyzing the causes of PSTS and the adequacy of provisions in FMA (Noise) $1989^{\circ}$ to prevent PSTS. The structured and hierarchal approach provides a standardized perspective of errors or faults within the system in preventing NIHL. Corrective measures should only be taken after the root cause has been traced back to the basic events. This step should be taken in order for the responsible party to have a clearer insight on the cause of the incident rather than to act blindly.

The limitation of this study is lack of probability data which can be used to calculate the risks and prioritize actions to be taken. These data would be invaluable in calculating the risk during revisit once appropriate corrective measures have been take

\section{REFERENCES}

1. Beresh, R., Anders, G., \& Ciufo, J. 2008. LS 10 Basic fault tree analysis for use in protection reliability. Int Journal Reliability \& Safety, 2, 64-78.

2. Butterworth, R. L. 2018. Minuteman for the Joint Fight. Strategic Studies Quarterly, 9(1), 3- 
16.

3. Kritzinger, D. 2017. Fault tree analysis. In Aircraft System Safety (pp. 59-99). http:// doi.org/10.1016/B978-0-08-100889-8.00004-0.

4. Dhillon, B. S. 2003. Methods for performing human reliability and error analysis in health care. International Journal of Health Care Quality Assurance, 16(6), 306-317. http:// doi.org/10.1108/09526860310495697.

5. Wreathall, J., \& Nemeth, C. 2004. Assessing risk: The role of probabilistic risk assessment (PRA) in patient safety improvement. Quality and Safety in Health Care, 13(3), 206-212. http://doi.org/10.1136/qshc.2003.006056.

6. Rogith, D., lyengar, M. S., \& Singh, H. 2017. Using fault trees to advance understanding of diagnostic errors. Joint Commission Journal on Quality and Patient Safety, 43(11), 598-605. http://doi.org/10.1016/j.jcjq.2017.06.007.

7. Abecassis, ZA, McElroy, LM, Patel, RM, Khorzad, R, Carroll, C, \& Mehrotra, S. 2015. Applying fault tree analysis to the prevention of wrong-site surgery. Journal of Surgical Research, 193(1), 88-94. http:// doi.org/10.1016/j.jss.2014.08.062.

8. Jonas, J. A., Devon, E. P., Ronan, J. C., Ng, S. C., Owusu-Mckenzie, J. Y., Strausbaugh, J. T., ... Hart, J. K. 2016. Determining preventability of pediatric readmissions using fault tree analysis. Journal of Hospital Medicine, 11(5), 329- 335. http://doi.org/10.1002/jhm.2555.

9. Federal Subsidiary Legislation. Factories And Machinery (Noise Exposure) Reglations. 1989, Pub. L. No. 139 1989. Malaysia.

10. Kirchner, D. B., Evenson, E., Dobie, R. A., Rabinowitz, P., Crawford, J., Kopke, R., \& Hudson, T. W. 2012. Occupational noiseinduced hearing loss. Journal of Occupational and Environmental Medicine, 54(1), 106-108. http://doi.org/10.1097/ JOM.0b013e318242 677d.

11. OSHA USA. 2002. Hearing Conservation Program for Construction Workers. Retrieved April 5, 2017, from https://www.osha.gov/ laws-regs/federalregister/2002-08-05.

12. Jonas, J. A., Devon, E. P., Ronan, J. C., Ng, S. C., Owusu-Mckenzie, J. Y., Strausbaugh, J. T., ... Hart, J. K. 2016. Determining preventability of pediatric readmissions using fault tree analysis. Journal of Hospital Medicine, 11(5), 329-335. http://doi.org/10.1002/jhm.2555.

13. United States Department of Labour. 2013.
Find it in OSHA. Retrieved April 6, 2018, from https://www.osha.gov/pls/oshaweb/ owadisp.show_document? p_table $=$ STANDARDS\&p_id $=9742$.

14. Laws, J. 2014. The Fit Testing Revolution. Hearing Protection, 83(5), 45-6. Retrieved from http://www.ncbi.nlm.nih.gov/ pubmed/10180297.

15. Colucci, D. A. 2014. Fit for hearing protection with earplug testing. Hearing Journal, 67(12), 40. http://doi.org/10.1097/ 01.HJ.0000459168.22417.73. 